\title{
Cardiovascular Disease Risk Factors in HIV- Infected Adults in Nyeri County, Kenya
}

\author{
Regina Kamuhu ${ }^{1}$, Beatrice Mugendi ${ }^{2}$, Judith Kimiywe ${ }^{3}$, Eliud Njagi ${ }^{4}$ \\ ${ }^{1}$ Food, Nutrition \& Dietetics Department, Kenyatta University, P.O BOX 43844-00100, Nairobi, Kenya. \\ ${ }^{2}$ Food and Nutrition Department, Murang'a University of Technology, P.O Box 75-10200, Murang'a, Kenya. \\ ${ }^{3}$ Food, Nutrition \& Dietetics Department, Kenyatta University, P.O BOX 43844-00100, Nairobi, Kenya. \\ ${ }^{4}$ Biochemistry And Biotechnology Department, Kenyatta University, P.O BOX 43844-00100, Nairobi, Kenya
}

Corresponding Author: Regina Kamuhu

\section{ABSTRACT}

Cardiovascular diseases (CVD) is currently second, after cancer, as the most frequent cause of death among HIV-positive subjects in areas of the world where Highly active anti-retroviral therapy (HAART) is widely available. The purpose of this study was to investigate cardiovascular disease markers in HIV-infected adults attending comprehensive care clinic in Nyeri Level- 5- Hospital. The results are based on a sample of 85 participants that randomly selected for an intervention study with two study arms. Descriptive statistics were used to analyze all study variables. Relationships between all and individual CVD risk factors were analyzed using Spearman's correlation coefficient. Criterion for statistical significance was at $\mathrm{p}<0.05$ and $90 \%$ power of test. Twenty nine percent of the respondents were aged fifty years and above while $48.2 \%$ were between $40-49$ years. Only $5.9 \%$ of the respondents smoked while $8.2 \%$ drunk alcohol. Twenty seven percent $(27.1 \%)$ had low physical activity while $24.7 \%$ had obesity class I (30-34.9), $8.2 \%$ had obesity class II (35-39.9) while $1.5 \%$ had obesity class III (> 40). Another 31.8\% were overweight (25-29.9). 28.2\% had hypertension stage I (140-159) and another $11.8 \%$ had hypertension stage II (>160). Twenty two percent (22.4\%) had high total cholesterol (>6.2), while $34.1 \%$ had high serum triglycerides $(2.25-5.6)$ and another $4.7 \%$ had very high serum LDL-C ( $>4.91)$. Framingham's risk score was used to determine the 10-year risk of developing a coronary heart disease. Majority of the participants $(60 \%)$ had low $(<10 \%) 10$-year risk of coronary heart disease at the baseline. There is a high prevalence of hypertension and overweight/obesity among HIV+ patients.

Key Words: Cardiovascular risk factors, cardiovascular risk score, lipid profile, Framingham risk score

\section{INTRODUCTION}

Factors linked to increased risk of CVD development have been classified as modifiable and non-modifiable. Included among the modifiable, traditional factors are; smoking, elevated LDL and non-HDL cholesterol and lack of exercise. Other factors comprising of the metabolic syndrome including insulin resistance, hypertension, elevated waist circumference, elevated triglycerides and low HDLcholesterol, are also modifiable. Nonmodifiable factors comprise of age, sex and genetic predisposition. (1-2) Furthermore, other emerging CVD risk factors have been identified in recent years; these include homocystinuria and high levels of Creactive protein. ${ }^{(1-2)}$ Latest data indicate that HIV infection and components of HAART may unfavorably affect multiple risk factors for CVD. Moreover, since age and sex are the major non-modifiable cardiovascular risk factors, the risk for CVD in this population is likely to increase in the near future. 
Alongside the changing landscape of HIV care, the burden of cardio metabolic diseases in SSA is rising, ${ }^{(3)}$ with deaths attributable to cardiovascular disease expected to double to 2.4 million in 2030 relative to reports from $2000 .{ }^{(4)}$ The data suggests that cardio metabolic illnesses would become a major health problem in SSA, competing with infectious diseases for limited health resources. ${ }^{(5)}$ Cardiovascular diseases (CVD) are presently the second most common cause of death (after cancer) among people living with HIV in regions of the world where highly active anti-retroviral therapy (HAART) is extensively available. (6)

\section{METHODOLOGY AND MATERIALS}

The results are based on a sample of 85 participants that randomly selected for an intervention study with two study arms. Anthropometric measurements were taken using different equipment. Height was measured using a stadiometer while waist and hip circumference were measured using an elastic tape. Body composition was also assessed using bioelectric impedance analyzer (Beurer GmbH, BF20). Blood pressure and heart rate were measured with an automatic blood pressure monitor (Visomat ${ }^{\circledR} \quad$ Comfort 20/40, Roche Diagnostics).

Fasting blood samples was collected in the morning between 7.00 and $8.00 \mathrm{am}$. Capillary blood was collected and tested for fasting blood glucose while approximately 5 $\mathrm{ml}$ of venous blood was collected for fasting lipid profile and transferred to heparinized collecting tubes. Lipid profile assays were routinely analyzed on Mindray BSseries auto analyzer (Mindray-Bio Medical $\mathrm{GmbH}$, Hamburg, and Germany) using established techniques. Fasting blood glucose was measured using soft-style Glucometer from Chemlabs. Framingham risk scores were used to estimate the 10 year risk of developing myocardial infarction. ${ }^{(7)}$ Nutrient intake was assesses using 24-hour recall. Ethical clearance was sought from
Kenyatta University Ethical Review Committee (REF:KU.R/COMM/51/273), permission was sought from NACOSTI (REF: NCST/RCD/12A/013/4) and informed consent obtained from the study participants.

\section{DATA ANALYSIS}

Descriptive statistics (frequencies, means, standard deviations, and percentages) were analyzed on the final cleaned data set for all study variables. For continuous variables, mean, median, skewness, standard error of the mean, standard deviation were calculated. Frequencies were run on all categorical variables. All continuous variables were checked for normal distribution by calculating Fisher's measure of skewness. ATP III, ${ }^{(7)}$ guidelines were used to classify risk for lipid profile: Total cholesterol of $<5.1 \mathrm{mmmol} / \mathrm{L}$ - desirable, 5.1-6.1 $\mathrm{mmol} / \mathrm{L}-$ borderline high and above $6.1 \mathrm{mmol} / \mathrm{L}$ high; Triglyceride $<1.69 \mathrm{mmol} / \mathrm{L}$ - normal, 1.69-2.24mmol/L- borderline high and 2.25$5.6 \mathrm{mmol} / \mathrm{L}-$ high and above $5.6 \mathrm{mmol} / \mathrm{L}-$ very high; HDL-C less than 1.03-low while above $1.55 \mathrm{mmol} / \mathrm{L}-\mathrm{high}$; LDL-C below $2.5 \mathrm{mmol} / \mathrm{L}$ - optimal, $2.5-3.3 \mathrm{mmol} / \mathrm{L}$ near optimal, 3.4-4.1 $\mathrm{mmol} / \mathrm{L}$ - borderline high, $4.2-4.9 \mathrm{mmol} / \mathrm{L}$ high and above $4.91 \mathrm{mmol} / \mathrm{L}$ - very high.

Diabetes risk classification was adopted from American Diabetes Association. ${ }^{(8)}$ : Fasting blood glucose below $100 \mathrm{mg} / / \mathrm{dl}$ - normal, $100-125 \mathrm{mg} / \mathrm{dl}-$ pre-diabetes and above $126 \mathrm{mg} / \mathrm{dl}$ - diabetes. Hypertension risk classification was adopted from National high blood pressure education program coordinating committee 7th report (2003): Systolic blood pressure $<120 \mathrm{mmHg}$ or diastolic blood pressure < $80 \mathrm{mmHg}$-normal; Systolic blood pressure $120-139 \mathrm{mmHg}$ or diastolic blood pressure 80-89mmHg-pre hypertension; Systolic blood pressure $140-159 \mathrm{mmHg}$ or diastolic blood pressure $90-99 \mathrm{mmHg}-$ Stage I hypertension; and Systolic blood pressure $\geq 160 \mathrm{mmHg}$ or diastolic blood pressure $\geq 100 \mathrm{mmHg}$ - Stage II hypertension. 


\section{RESULTS}

\subsection{Baseline cardiovascular risk factors}

Table 1 shows a description of baseline cardiovascular risk factors. The cut offs for lipid profile were based on NCEP ATP 111. ${ }^{(7)}$ Guidelines while obesity was classified using WHO guidelines. ${ }^{(9)}$ Waist hip ratio and waist circumference were based on WHO guidelines. ${ }^{(10)}$ Twenty nine percent of the respondents were aged fifty years and above while $48.2 \%$ were between 40-49 years. Only $5.9 \%$ of the respondents smoked while $8.2 \%$ drunk alcohol. Twenty seven percent $(27.1 \%)$ had low physical activity while only $11.8 \%$ had high physical activity. Twenty four percent $(24.7 \%)$ had obesity class I (30-34.9), 8.2\% had obesity class II (35-39.9) while 1.5\% had obesity class III (> 40). Another $31.8 \%$ were overweight (25-29.9). Slightly over $8 \%$ of the males had WHR of 0.96-1 (moderate risk) while $3.5 \%$ had high risk (WHR >1). Nineteen females $(22.4 \%)$ had moderate risk (WHR 0.81-0.85) while 42.9\% had high risk (WHR >0.85). Systolic blood pressure was used to determine the hypertension status. Over $40 \%$ of the respondents were found to be pre hypertensive (120-139) while $28.2 \%$ had hypertension stage I (140-159) and another $11.8 \%$ had hypertension stage II $(>160)$. This high prevalence was also reported by ${ }^{(11)}$ who found the prevalence of pre hypertension and hypertension in western Kenya to be $30.8 \%$ and $20 \%$, respectively. Prevalence of hypertension among HIV positive patients in Thika District Hospital was 18\% (95\% Confidence Interval $[C]: 12.5-23.5 \%$ ) who have also used the same classification for hypertension. (12) Twenty two percent $(22.4 \%)$ had high total cholesterol (>6.2), $30.6 \%$ had borderline high (5.1-6.1) while $47.1 \%$ had desirable levels. Over $21 \%$ of the respondents had borderline high triglyceride (1.69-2.24) while $34.1 \%$ had high serum triglycerides (2.25-5.6). Only 5.9\% had low serum levels of HDL-C $(<1.03)$ while $34.1 \%$ had high serum HDL-C (>1.55). Twenty nine percent of the respondents had borderline high serum levels of LDL-C (3.4-
4.1) while $7.1 \%$ had high (4.2-4.9) and another $4.7 \%$ had very high serum LDL-C (>4.91).

\begin{tabular}{|c|c|c|}
\hline Risk factor & Category & Total \\
\hline \multirow[t]{4}{*}{ Age } & $18-29$ & $1(1.2)$ \\
\hline & $30-39$ & $18(21.2)$ \\
\hline & $40-49$ & $41(48.3)$ \\
\hline & $>50$ & $25(39.4)$ \\
\hline \multirow[t]{3}{*}{ Smoking } & Yes & $5(5.9)$ \\
\hline & Never & $77(90.6)$ \\
\hline & Not in the last 1 year & $3(3.5)$ \\
\hline \multirow[t]{2}{*}{ Alcohol consumption } & Yes & $7(8.2)$ \\
\hline & No & $78(91.8)$ \\
\hline \multirow[t]{3}{*}{ Physical activity } & Low & $23(27.1)$ \\
\hline & Moderate & $52(61.2)$ \\
\hline & High & $10(11.8)$ \\
\hline \multirow[t]{6}{*}{$\mathrm{BMI}\left(\mathrm{kg} / \mathrm{m}^{2}\right)$} & Less than 18.5 & $2(2.4)$ \\
\hline & $18.5-24.9$ & $27(31.8)$ \\
\hline & $25-29.9$ & $27(31.8)$ \\
\hline & $30-34.9$ & $21(24.7)$ \\
\hline & $35-39.9$ & $7(8.2)$ \\
\hline & $>40$ & $1(1.2)$ \\
\hline \multirow[t]{3}{*}{ WHR (male) } & 0.95 and below & $8(9.4)$ \\
\hline & 0.96 to 1 & $7(8.2)$ \\
\hline & above 1 & $3(3.5)$ \\
\hline \multirow[t]{3}{*}{ (Females ) } & 0.80 and below & $6(7.1)$ \\
\hline & 0.81 to 0.85 & $19(22.4)$ \\
\hline & above 0.85 & $42(49.4)$ \\
\hline \multirow[t]{4}{*}{$\mathrm{SBP}(\mathrm{mmHg})$} & less than 120 & $15(17.6)$ \\
\hline & 120 to 139 & $36(42.4)$ \\
\hline & 140 to 159 & $24(28.2)$ \\
\hline & 160 and above & $10(11.8)$ \\
\hline \multirow[t]{3}{*}{$\mathrm{TC}(\mathrm{mmol} / \mathrm{L})$} & less than 5.1 & $40(47.1)$ \\
\hline & 5.1 to 6.1 & $26(30.6)$ \\
\hline & 6.2 and above & $19(22.4)$ \\
\hline \multirow[t]{3}{*}{$\mathrm{TG}(\mathrm{mmol} / \mathrm{L})$} & less than 1.69 & $40(47.1)$ \\
\hline & 1.69 to 2.24 & $18(21.2)$ \\
\hline & 2.25 to 5.6 & $27(31.8)$ \\
\hline \multirow[t]{3}{*}{ HDL-C(mmol/L) } & less than 1.03 & $12(14.1)$ \\
\hline & 1.03 to 1.54 & $44(51.8)$ \\
\hline & 1.55 and above & $29(34.1)$ \\
\hline \multirow[t]{5}{*}{ LDL-C(mmol/L) } & $<2.5$ & $16(18.8)$ \\
\hline & 2.5 to 3.3 & $31(36.5)$ \\
\hline & 3.4 to 4.1 & $25(29.4)$ \\
\hline & 4.2 to 4.9 & $6(7.1)$ \\
\hline & $>4.91$ & $7(8.2)$ \\
\hline \multirow[t]{3}{*}{ FBG (mg/dl) } & less than 100 & $71(83.5)$ \\
\hline & 100 to 126 & $9(10.6)$ \\
\hline & 126 and above & $5(5.9)$ \\
\hline
\end{tabular}

Numbers in parenthesis indicate the percentage frequency

\subsection{Assessment of 10-year risk of developing a coronary heart disease.}

Framingham's risk score was used to determine the 10-year risk of developing a coronary heart disease. Table 2 shows the Framingham's risk score at baseline. Majority of the participants $(60 \%)$ had low $(<10 \%)$ 10-year risk of coronary heart disease at the baseline while $2.4 \%$ of the participants had medium (20-30\%) 10-year risk of coronary heart disease. There was no 
significant difference in the risk between males and females $(p>0.05)$ at baseline.

Table 2: Framingham's risk scores

\begin{tabular}{|c|c|c|c|}
\hline & Male & Female & P value (chi) \\
\hline$<10 \%$ & $9(10.6)$ & $42(49.4)$ & 0.08 \\
\hline $10-20 \%$ & $7(8.2)$ & $25(29.4)$ & \\
\hline $20-30 \%$ & $2(2.4)$ & $0(0.0)$ & \\
\hline$>30 \%$ & $0(0.0)$ & $0(0.0)$ & \\
\hline
\end{tabular}

\section{Relationship between variables}

In table three (APPENDIX),

Pearson's correlation test was used to test relationship between the risk factors and Framingham's risk score. Gender correlated with body mass index $(\mathrm{r}(85)=0.244, \mathrm{p}<$ $0.05)$, serum triglycerides $(\mathrm{r}(85)=-0.371, \mathrm{p}$ $<0.01)$ and Framingham's risk score ( $\mathrm{r}(85)$ $=-0.605, \mathrm{p}<0.01)$. Age correlated with blood pressure $(\mathrm{r}(85)=0.390, \mathrm{p}<0.01)$ and Framingham's risk scores $(\mathrm{r}(85)=0.541, \mathrm{p}$ $<0.01)$ while smoking only correlated with Framingham's risk score $(\mathrm{r}(85)=-0.443, \mathrm{p}$ $<0.01)$. Physical activity correlated with blood pressure while BMI correlated with waist circumference $(\mathrm{r}(85)=0.777, \mathrm{p}<$ $0.01)$, hip circumference $(\mathrm{r}(85)=0.864, \mathrm{p}<$ $0.01)$ and blood pressure ( $(85)=0.262, \mathrm{p}<$ $0.05)$. Total cholesterol correlated with triglycerides $(\mathrm{r}(85)=0.262, \mathrm{p}<0.05)$, serum LDL-C $(\mathrm{r}(85)=0.777, \mathrm{p}<0.01)$ and Framingham's risk scores $(\mathrm{r}(85)=0.459, \mathrm{p}$ $<0.01)$. Serum triglycerides correlated with HDL-C (r (85) = -0.351, p < 0.01), LDL-C $(\mathrm{r} \quad(85)=-0.271, \mathrm{p}<0.05)$ and Framingham's risk scores $(\mathrm{r}(85)=0.256, \mathrm{p}$ $<$ 0.05). LDL-C correlated with Framingham's score $(\mathrm{r}(85)=0.425, \mathrm{p}<$ 0.01).

\section{DISCUSSION}

Estimates were that by the year 2015, more than $50 \%$ of all HIV-positive patients would be more than 50 years old; a situation resulting from the significant decline in mortality due to HAART. (14) Hypertension has emerged as an important medical and public health issue in SSA, having been identified as a major risk factor for CVD. This is occurring despite the ravage being perpetuated by tuberculosis, HIV and malaria. ${ }^{(15)}$

Other major and well-known modifiable risk factors for CVD are overweight and obesity whose prevalence is growing in SSA is despite the existing competing epidemic of malnutrition ${ }^{(16)}$ and substance use whose disorders and CVD are often co-morbid. Alcohol consumption and tobacco use remains among the most serious epidemiological risk factors for prevalence of coronary artery disease. ${ }^{(17)}$

Highly active anti-retroviral therapy (HAART) associated dyslipidemia is characterized by hypertriglyceridemia with low plasma concentrations of high-density lipoprotein (HDL) cholesterol and increased total cholesterol, with or without increased low-density (LDL) cholesterol. (18) Dyslipidemia refers to hypercholesterolemia (high serum total cholesterol) and hypoalphalipoproteinemia (low serum alpha lipoprotein) which refers to an abnormal metabolism of plasma lipids. Genetic, dietary or secondary disease factors can cause this abnormal metabolism. The major classes of plasma lipids are cholesterol, cholesterol esters, triglyceride and phospholipids. ${ }^{(19)}$ Dyslipidemia, consisting of hypertriglyceridemia together with depressed concentrations of high density lipoprotein cholesterol and elevated lowdensity lipoproteins cholesterol, is increasing among people living with HIV. The use of Highly Active Anti-Retroviral Therapy (HAART) has converted HIV infection into a chronic manageable disease. (20)

Findings from developed countries suggest that PI use may be driving both hypertension and obesity. ${ }^{(21)}$ However, in contrast to studies from developed countries, it is unlikely that use of protease inhibitors were a major cause of obesity in our sample since the proportion of people using PIs was low (5.9\%). This increase in hypertension prevalence could be explained by high BMI observed as there is a positive correlation between BMI and high blood pressure. High waist and hip circumference 
seen in this population could also have contributed to the high prevalence of hypertension as there is a positive correlation observed between these two variables. Age is also seen to positively correlate with BMI in this study as majority of the participants were aged forty years and above.

These results are consistent with ${ }^{(22)}$ whose study in Kenyatta National Hospital found the prevalence of hypercholesterolemia to be $39.2 \%$, elevated LDL-C to be $40 \%$, low HDL-C to be $14.6 \%$ and high triglycerides to be $25.6 \%$. Molla et al. (2014) ${ }^{(23)}$ studied dyslipidemia in HIV positive patients on ART in Addis Ababa Ethiopia and found that $23 \%$ had high LDLC, $46.8 \%$ had high triglycerides, $42 \%$ had high total cholesterol and $50.8 \%$ had low HDLC. Antiretroviral therapy may exacerbate lipid abnormalities and dyslipidemia may develop in up to $70 \%$ and $80 \%$ of HIV-infected patients with hypertriglyceridemia occurring in majority of cases $(60 \%$ to $100 \%)$ of treated patients. The presence of hypertriglyceridemia enhances development of small, dense low density lipoproteins particles. (24) Norman and colleagues found that high serum cholesterol level $(\geq 3.8 \mathrm{mmol} / \mathrm{l})$ accounted for 59 percent of ischemic heart disease and 29 percent of ischemic stroke burden in adults age 30 and over.

This study found that $4 \%$ had pre diabetes $(100-126 \mathrm{mg} / \mathrm{dl})$ while $5 \%$ had diabetes (> 126mg/dl). Dysglycemia was also reported by ${ }^{(22)}$ at $20.7 \%$ among HIV patients while ${ }^{(23)}$ reported prevalence of Dysglycemia at $7.5 \%$. The prevalence of diabetes in this study is higher than the national prevalence which is $3.5 \%$ (Shaw et al., 2010). This could be due to small sample as compared to the national sample. The results also agree with studies done in developed countries. Among HIV-infected adults with lipoatrophy or fat accumulation, diabetes mellitus was seen in $7.0 \%$, as compared with $0.5 \%$ of otherwise healthy control subjects matched for age and bodymass index. ${ }^{(25)}$
Impaired glucose tolerance was present in more than $35 \%$ of HIV-infected subjects as compared with $5 \%$ of otherwise healthy control subjects matched for age and body-mass index. ${ }^{(25)}$ Antiretroviral therapy may also alter glucose homeostasis. Protease inhibitors (including Indinavir, Amprenavir, Nelfinavir, and Ritonavir (26-28) have been shown to induce insulin resistance in vitro by reducing glucose transport mediated by glucose transporter 4 . (26) This is seen to occur without affecting postreceptor insulin signaling. Protease inhibitors may also decrease pancreatic beta-cell insulin secretion ${ }^{(29)}$ but insulin resistance is seen to be the primary defect. Direct effects of nucleoside analogues on glucose metabolism have not been demonstrated, but such drugs may contribute to insulin resistance indirectly through changes in fat distribution.

Smoking and alcohol consumption were low in this study. The rates of smoking were $1.2 \%$ for females and $4.7 \%$ for males. This is lower than the estimated national prevalence for smoking which is $1.5 \%$ for females and $25.5 \%$ for males. ${ }^{(30)}$ This is comparable to studies done elsewhere since men tend to consume more alcohol and smoke more cigarettes than females as found in Kenyan surveys CBS 2003, KNBS and ICF Macro 2008-09. In these surveys, about $2 \%$ of women used tobacco in its various forms whereas $1 \%$ smoked cigarettes.

This study assessed the cardiovascular disease risk factor and their correlation to Framingham's risk score that predicts 10-year risk of developing coronary heart disease. The study found correlation between Framingham's risk score with age, sex, body fat blood pressure, total cholesterol, and LDL cholesterol. Similar results have been highlighted by ${ }^{(31)}$ in a review of Cardiovascular Risk Factors: Insights from Framingham Heart Study.

\section{CONCLUSION}

In central Kenya, there is a high prevalence of hypertension and overweight/ 
obesity among HIV+ patients. Even though the 10-year risk of developing a coronary heart disease is relatively low, age, sex, body fat, blood pressure, total cholesterol, and LDL cholesterol are found to be major contributors The care of HIV+ patients in sub-Saharan Africa should also include both identification and management of associated cardiovascular risk factors.

\section{ACKNOWLEDGEMENT}

I wish to acknowledge my coauthors, Nyeri Level 5 hospital and the participants in the study.

\section{Conflict of Interest: None}

\section{Source of Funding: None}

\section{Ethical Approval: Approved}

\section{REFERENCES}

1. Grundy SM, Pasternak R, Greenland P, Smith Jr S, Fuster V. Assessment of cardiovascular risk by use of multiple-riskfactor assessment equations: A statement for healthcare professionals from the American Heart Association and the American College of Cardiology. Journal of the American College of Cardiology. 1999 Oct 1;34(4):1348-59.

2. Hackam DG, Anand SS. Emerging risk factors for atherosclerotic vascular disease: a critical review of the evidence. Jama. 2003 Aug 20;290(7):932-40.

3. Aikins $\mathrm{AD}$, Boynton $\mathrm{P}$, Atanga LL. Developing effective chronic disease interventions in Africa: insights from Ghana and Cameroon. Globalization and health. 2010 Dec 1;6(1):6.

4. WHO.

(2009).http://www.who.int/healthinfo/global _burden_disease/projections/en/index.html

5. Maher D, Waswa L, Baisley K, Karabarinde A, Unwin N, Grosskurth H. Distribution of hyperglycaemia and related cardiovascular disease risk factors in low-income countries: a cross-sectional population-based survey in rural Uganda. International Journal of Epidemiology. 2011 Feb 1;40(1):160-71.

6. Effros RB, Fletcher CV, Gebo K, Halter JB, Hazzard WR, Horne FM, Huebner RE, Janoff EN, Justice AC, Kuritzkes D,
Nayfield SG. Workshop on HIV infection and aging: what is known and future research directions. Clinical infectious diseases: an official publication of the Infectious Diseases Society of America. 2008 Aug 15;47(4):542.

7. Executive Summary of the Third Report of the National Cholesterol Education Program (NCEP) Expert Panel on Detection, Evaluation, And Treatment of High Blood Cholesterol In Adults (Adult Treatment Panel III). JAMA 2001; 285:2486-2497

8. MELLITUS D. Diagnosis and Classification of Diabetes Mellitus. DIABETES CARE. 2008 Jan 1;31:S55.

9. World Health Organization. Global HIV/AIDS response: epidemic update and health sector progress towards universal access: progress report 2011.

10. Consultation WE. Waist circumference and waist-hip ratio. Report of a WHO Expert Consultation. Geneva: World Health Organization. 2008 Dec;2008:8-11.

11. Bloomfield GS, Hogan JW, Keter A, Sang E, Carter EJ, Velazquez EJ, Kimaiyo S. Hypertension and obesity as cardiovascular risk factors among HIV seropositive patients in Western Kenya. PloS one. 2011 Jul 14;6(7):e22288.

12. Njeru JI. Prevalence and Associated Risk Factors for Hypertension among HIV Positive Patients Attending Comprehensive Care Centre at Thika District Hospital, Kenya, 2008 (Doctoral dissertation).

13. Mancia G, De Backer G, Dominiczak A, Cifkova R, Fagard R, Germano G, Grassi G, Heagerty AM, Kjeldsen SE, Laurent S, Narkiewicz K. 2007 Guidelines for the management of arterial hypertension: The Task Force for the Management of Arterial Hypertension of the European Society of Hypertension (ESH) and of the European Society of Cardiology (ESC). European heart journal. 2007 Jun 1;28(12):1462-536.

14. Effros RB, Fletcher CV, Gebo K, Halter JB, Hazzard WR, Horne FM, Huebner RE, Janoff EN, Justice AC, Kuritzkes D, Nayfield SG. Workshop on HIV infection and aging: what is known and future research directions. Clinical infectious diseases: an official publication of the Infectious Diseases Society of America. 2008 Aug 15;47(4):542. 
15. Gill GV, Mbanya JC, Ramaiya KL, Tesfaye S. A sub-Saharan African perspective of diabetes. Diabetologia. 2009 Jan 1;52(1):8.

16. Holdsworth M, Gartner A, Landais E, Maire B, Delpeuch F. Perceptions of healthy and desirable body size in urban Senegalese women. International journal of obesity. 2004 Dec;28(12):1561-8.

17. Verdier F, Fourcade L. Evolution Of Cardiovascular Risk Factors In Developing Countries. Tropical medicine. 2007; 67 (7): 552-8.

18. Penzak SR, Chuck SK. Hyperlipidemia associated with HIV protease inhibitor use: pathophysiology, prevalence, risk factors and treatment. Scandinavian journal of infectious diseases. 2000 Jan 1;32(2):11123.

19. Ghose TC. Dyslipidaemia: A major risk factor for coronary artery diseases and new strategy of its management. ORION. 2006 Sep;25.

20. Mocroft A, Ledergerber B, Katlama C, Kirk $\mathrm{O}$, Reiss PD, Monforte AD, Knysz B, Dietrich M, Phillips AN, Lundgren JD, EuroSIDA Study Group. Decline in the AIDS and death rates in the EuroSIDA study: an observational study. The Lancet. 2003 Jul 5;362(9377):22-9.

21. Kaplan RC, Kingsley LA, Sharrett AR, Li $\mathrm{X}$, Lazar J, Tien PC, Mack WJ, Cohen MH, Jacobson L, Gange SJ. Ten-year predicted coronary heart disease risk in HIV-infected men and women. Clinical Infectious Diseases. 2007 Oct 15;45(8):1074-81.

22. Manuthu EM, Joshi MD, Lule GN, Karari E. Prevalence of dyslipidemia and dysglycaemia in HIV infected patients. East African medical journal. 2008 May 28; 85(1): 10-7.

23. Abebe M, Kinde S, Belay G, Gebreegziabxier A, Challa F, Gebeyehu T, Nigussie P, Tegbaru B. Antiretroviral treatment associated hyperglycemia and dyslipidemia among HIV infected patients at Burayu Health Center, Addis Ababa, Ethiopia: a cross-sectional comparative study. BMC research notes. 2014 Dec 1;7(1):380.

24. Manfredi R. High-risk dysmetabolism disorders associated with HAART-treated HIV disease, and reimbursement of lipidlowering drugs, in a clinical and a socioeconomic perspective. AIDS reviews. 2005;7(3):155.
25. Mayere KH, Hadigan C, Jeste S, Anderson EJ, Tsay R, Cyr H, Grinspoon S. Modifiable dietary habits and their relation to metabolic abnormalities in men and women with human immunodeficiency virus infection and fat redistribution. Clinical Infectious Diseases. 2001 Sep 1;33(5):710-7.

26. Murata H, Hruz PW, Mueckler M. The mechanism of insulin resistance caused by HIV protease inhibitor therapy. Journal of Biological Chemistry. 2000 Jul 7;275(27): 20251-4.

27. Rudich A, Vanounou S, Riesenberg K, Porat M, Tirosh A, Harman-Boehm I, Greenberg AS, Schlaeffer F, Bashan N. The HIV protease inhibitor nelfinavir induces insulin resistance and increases basal lipolysis in 3T3-L1 adipocytes. Diabetes. 2001 Jun 1;50(6):1425-31.

28. Ben-Romano R, Rudich A, Török D, Vanounou S, Riesenberg K, Schlaeffer F, Klip A, Bashan N. Agent and cell-type specificity in the induction of insulin resistance by HIV protease inhibitors. Aids. 2003 Jan 3;17(1):23-32.

29. Woerle HJ, Mariuz PR, Meyer C, Reichman RC, Popa EM, Dostou JM, Welle SL, Gerich JE. Mechanisms for the deterioration in glucose tolerance associated with HIV protease inhibitor regimens. Diabetes. 2003 Apr 1;52(4):918-25.

30. BeLue R, Okoror TA, Iwelunmor J, Taylor KD, Degboe AN, Agyemang C, Ogedegbe G. An overview of cardiovascular risk factor burden in sub-Saharan African countries: a socio-cultural perspective. Globalization and health. 2009 Dec 1;5(1):10.

31. O'Donnell CJ, Elosua R. Cardiovascular risk factors. Insights from framingham heart study. Revista Española de Cardiología (English Edition). 2008 Jan 1;61(3):299310.

32. Wangui KR. Impact of peanut supplementation on cardiovascular disease markers in HIV-infected adults with dyslipidemia attending Nyeri level-5hospital, Kenya (doctoral dissertation, Kenyatta University) 2016.

How to cite this article: Kamuhu R, Mugendi B, Kimiywe $\mathrm{J}$ et.al. Cardiovascular disease risk factors in HIV-infected adults in Nyeri County, Kenya.Int J Health Sci Res.2021;11(5):117-124. DOI: https://doi.org/10.52403/ijhsr.20210516 


\section{APPENDIX}

Table 3: Relationship between risk factors and Framingham's scores

\begin{tabular}{|c|c|c|c|c|c|c|c|c|c|c|c|c|c|}
\hline & SEX & AGE & EDU & OCC & MAR & SMOK & ALC & P E & BMI & BF & WC & $\mathrm{HC}$ & BP \\
\hline SEX & 1 & $-.262^{*}$ & .015 & $-.217^{*}$ & .106 & .148 & .054 & .012 & $.244^{*}$ & $.723^{* *}$ & .010 & $.335^{* *}$ & .005 \\
\hline AGE & & 1 & .123 & -.120 & $.246^{*}$ & -.062 & .135 & -.093 & -.113 & -.105 & .095 & -.075 & $.390^{* *}$ \\
\hline EDU & & & 1 & $-.325^{* * 6}$ & -.097 & -.008 & .105 & .205 & -.025 & .100 & -.025 & .027 & -.098 \\
\hline OCC & & & & 1 & -.035 & .109 & -.127 & -.140 & -.009 & -.173 & .108 & -.028 & -.012 \\
\hline MAR & & & & & 1 & .093 & .117 & -.101 & .027 & .148 & .158 & .043 & .176 \\
\hline SMK & & & & & & 1 & .117 & -.147 & .180 & .159 & .097 & .121 & -.016 \\
\hline ALC & & & & & & & 1 & -.005 & .003 & .056 & .096 & -.011 & .124 \\
\hline P E & & & & & & & & 1 & -.008 & -.105 & .023 & -.017 & $-.219^{*}$ \\
\hline BMI & & & & & & & & & 1 & $.710^{* *}$ & $.777^{* *}$ & $.864^{* *}$ & $.262^{*}$ \\
\hline BF & & & & & & & & & & 1 & $.473^{* *}$ & $.702^{* *}$ & .156 \\
\hline WC & & & & & & & & & & & 1 & $.730^{* * *}$ & $.413^{* *}$ \\
\hline HC & & & & & & & & & & & & 1 & $.279^{* *}$ \\
\hline BP & & & & & & & & & & & & & 1 \\
\hline FBG & & & & & & & & & & & & & \\
\hline TC & & & & & & & & & & & & & \\
\hline TG & & & & & & & & & & & & & \\
\hline HDLC & & & & & & & & & & & & & \\
\hline LDLC & & & & & & & & & & & & & \\
\hline FAT & & & & & & & & & & & & & \\
\hline FIBRE & & & & & & & & & & & & & \\
\hline ENERG & & & & & & & & & & & & & \\
\hline PUFA & & & & & & & & & & & & & \\
\hline CHL & & & & & & & & & & & & & \\
\hline SAT & & & & & & & & & & & & & \\
\hline MUFA & & & & & & & & & & & & & \\
\hline VITE & & & & & & & & & & & & & \\
\hline F RISK & & & & & & & & & & & & & \\
\hline
\end{tabular}

\begin{tabular}{|c|c|c|c|c|c|c|c|c|c|c|c|c|c|}
\hline FBG & TC & TG & HDLC & LDLC & FAT & FIBRE & ENER & PUFA & CHL & SAT & MUFA & VITE & F RISK \\
\hline .001 & -.189 & $-.371^{* *}$ & .187 & -.200 & -.294 & .222 & -.465 & -.190 & -.143 & -.352 & -.431 & .341 & $-.605^{* *}$ \\
\hline .031 & .129 & .120 & .026 & .154 & -.395 & -.303 & -.094 & -.207 & -.221 & -.228 & -.160 & $-.636^{* *}$ & $.541^{* *}$ \\
\hline .088 & -.011 & .106 & -.181 & .100 & .174 & -.285 & .372 & .160 & .401 & .173 & .176 & .364 & .054 \\
\hline-.092 & -.112 & .082 & -.010 & -.092 & -.048 & .188 & -.251 & -.232 & -.254 & -.149 & -.196 & -.252 & -.023 \\
\hline .101 & -.177 & .006 & .078 & -.127 & .285 & -.115 & .255 & .354 & $.578^{*}$ & .278 & .259 & .227 & -.005 \\
\hline .150 & -.205 & .008 & -.048 & -.195 & .075 & -.169 & .243 & -.003 & .157 & .124 & .121 & .099 & $-.443^{* *}$ \\
\hline .156 & .102 & .026 & -.032 & .077 & .050 & .252 & .112 & .160 & .190 & .099 & .156 & .282 & .055 \\
\hline .028 & -.193 & -.026 & -.146 & -.180 & -.384 & .102 & -.195 & -.032 & -.209 & -.386 & -.333 & -.171 & -.038 \\
\hline .170 & -.051 & .007 & -.032 & .036 & -.426 & .352 & -.341 & -.169 & -.391 & -.358 & -.351 & .166 & -.187 \\
\hline .129 & -.069 & -.199 & .052 & -.026 & -.311 & .227 & $-.484^{*}$ & -.170 & -.180 & -.357 & -.393 & .269 & $-.350^{* *}$ \\
\hline $.239^{*}$ & -.028 & .100 & -.065 & .009 & -.339 & .263 & -.204 & -.108 & -.310 & -.303 & -.296 & -.017 & .046 \\
\hline .086 & -.136 & -.113 & .032 & -.033 & -.335 & -.064 & -.481 & -.414 & -.429 & -.318 & -.365 & .249 & -.205 \\
\hline .013 & .131 & -.012 & .077 & .105 & -.394 & .141 & -.477 & -.246 & -.317 & -.363 & -.429 & -.016 & $.301^{* *}$ \\
\hline \multirow[t]{14}{*}{1} & .005 & .016 & -.111 & .003 & .155 & .064 & .057 & $.554^{*}$ & .467 & -.097 & .019 & .270 & -.076 \\
\hline & 1 & $.252^{*}$ & .080 & $.777^{* *}$ & .058 & -.188 & .388 & .153 & .190 & .308 & .349 & .097 & $.459^{* *}$ \\
\hline & & 1 & $-.351^{* *}$ & $.271^{*}$ & -.096 & .133 & .472 & .168 & -.038 & .080 & .181 & $-.536^{*}$ & $.256^{*}$ \\
\hline & & & 1 & .067 & .061 & .028 & -.415 & -.050 & .140 & .001 & -.093 & .371 & -.071 \\
\hline & & & & 1 & .043 & -.355 & .411 & .078 & .092 & .120 & .236 & -.055 & $.425^{* *}$ \\
\hline & & & & & 1 & -.128 & $.571^{*}$ & $.649^{* *}$ & $.813^{* *}$ & $.821^{* *}$ & $.830^{* *}$ & $.494^{*}$ & .018 \\
\hline & & & & & & 1 & -.133 & .134 & -.060 & -.085 & -.103 & .195 & -.433 \\
\hline & & & & & & & 1 & $.582^{*}$ & $.658^{* *}$ & $.677^{* *}$ & $.750^{* *}$ & .070 & .235 \\
\hline & & & & & & & & 1 & $.870^{* *}$ & .466 & $.636^{* * *}$ & .159 & -.013 \\
\hline & & & & & & & & & 1 & $.668^{* *}$ & $.743^{* *}$ & .357 & -.096 \\
\hline & & & & & & & & & & 1 & $.952^{* *}$ & .443 & .176 \\
\hline & & & & & & & & & & & 1 & .300 & .234 \\
\hline & & & & & & & & & & & & 1 & -.465 \\
\hline & & & & & & & & & & & & & 1 \\
\hline
\end{tabular}

Correlation is significant at the 0.05 level (2-tailed). **. Correlation is significant at the 0.01 level (2-tailed).BMI- body mass index, LBMlean body muscle, W.C-waist circumference, H.C-hip circumference, SBP-systolic blood pressure, DBP-diastolic blood pressure, FBGfasting blood glucose TC-total cholesterol, TG-triglycerides, HDL-C high density lipoprotein cholesterol, LDL-C-low density lipoprotein cholesterol, F-risk-Framingham's risk score, PUFA-poly unsaturated fatty acid, MUFA- mono unsaturated fatty acids, CHL-cholesterol, OCC-occupation, SMK-smoking, ACL-alcohol, BF-body fat, MAR-marital status, EDU-education level 